\title{
Parametric Assessment of Equivalent Static Procedure Accounting for Foundation Pinning Effects in Analysis of Piled Bridge Abutments Subject to Lateral Spreading
}

\author{
Christopher R. McGann ${ }^{1}$,
}

\begin{abstract}
Foundation pinning is a critical consideration for design and analysis of bridge foundations subject to liquefaction-induced lateral spreading, particularly for bridges with a standard approach embankment of finite width. The simplified analysis procedure that has been generally adopted for this case makes consideration for foundation pinning effects by considering the compatibility between the near-field soil and foundation displacements, however, there is a lack of guidance or evidence indicating the practical limitations of the simplified method. This paper discusses the results of a large parametric study carried out using 3D finite element models and simplified analysis models of corresponding site conditions. This study is designed to identify the range of conditions where the simplified method produces reasonable results and to determine the expected reduction in near-field displacements relative to those in the free-field for different site geometries such that future applications of the simplified pile pinning analysis procedure will have a benchmark for comparison.
\end{abstract}

Keywords: lateral spreading, pile pinning, bridge abutments, deep foundations,

\section{INTRODUCTION}

Observations of foundation pinning at bridges affected by liquefaction-induced lateral spreading have been made following numerous previous earthquakes (Youd, 1993; Berrill et al., 2001; Ledezma et al., 2012; Wotherspoon et al., 2011; Palermo et al., 2017) for sites with finite-width approach embankments. At these sites, it is evident that the reaction forces

\footnotetext{
${ }^{1}$ Senior Lecturer, Department of Civil and Natural Resources Engineering, University of Canterbury, Private Bag 4800, Christchurch, New Zealand. email: christopher.mcgann@canterbury.ac.nz
} 
developed in the deep foundation and superstructure during lateral spreading (foundation pinning forces) have modified the soil deformation pattern such that the near-field lateral spreading displacements are reduced relative to the free-field displacements. This response is characterised by slumping and outward movement of the approach embankment fill due to liquefaction of the underlying material, and often the only post-earthquake repairs necessary involve the roadway and pavement rather than the bridge structure.

Due to the near-field reduction in soil deformation caused by foundation pinning, it can be significantly overconservative to ignore pinning effects and design bridge foundations to accommodate lateral spreading forces and deformations estimated using an empirical model based on free-field conditions (e.g., Youd et al., 2002; Zhang et al., 2004). A widely-adopted approach to account for foundation pinning effects in the analysis and design of bridge foundation for lateral spreading is a simplified equivalent static analysis (ESA) procedure that seeks near-field compatibility between the soil deformation, driving forces, and structural resistance developed in the soil-foundation system under lateral spreading (Martin et al., 2002; Boulanger et al., 2006; Ashford et al., 2011). The ESA procedure achieves this compatibility by comparing the results of two analytical phases: (1) a foundation pushover analysis typically conducted using a beam on nonlinear Winkler foundation (BNWF) representation of the soil-foundation system to determine the forces in the system for different levels of lateral spreading deformation, and (2) a pseudostatic seismic slope stability analysis combined with a Newmark sliding block analysis to assess expected levels of deformation for different ground motion intensities and different levels of mobilized foundation pinning force.

Lateral spreading is an enormously challenging phenomenon to account for in bridge foundation design. There are many factors that contribute to the development and subsequent effects of lateral spreading at a particular site, and as demonstrated by the observations and analyses of Turner and Brandenberg (2015) and Ghofrani et al. (2016), the deformation and load transfer mechanisms that develop at bridge sites subject to lateral spreading are quite complex. Due to these challenges, verification and validation of analytical or numerical de- 
sign tools is a critical need to ensure they can be used with confidence in the situations where they work and avoided in the situations where they don't work. In regard to the ESA procedure, previous validation and verification efforts by Armstrong et al. (2014) and McGann and Arduino (2014) have demonstrated that the ESA procedure performed well under the considered conditions for a simplified archetype case of a single piled bridge abutment with a finite-width approach embankment subject to lateral spreading parallel to the longitudinal direction of the bridge. Though these results are encouraging, the ESA procedure has not been extensively validated or verified against a large range of different conditions.

In this paper, a parametric study is undertaken to provide further verification of the ESA procedure, specifically in regard to how variations in embankment width, soil profile layout, and deep foundation stiffness affect the foundation demands and reductions in near-field soil deformation relative to the free-field for a simple, single deep foundation model. To achieve this verification, the compatible displacements returned by the ESA are compared to the results of three-dimensional finite element analyses (3D FEA) developed for corresponding variations in the considered parameters. The models are designed to be as simple as possible while still capturing the core elements of the problem. To this purpose, the models consider a simplified site geometry with only a single deep foundation rather than a group. While this does not correspond to actual abutment foundation designs, which will almost certainly involve grouped foundations, it allows for the core aspects of the laterally-loaded deep foundation problem to be considered in the simplest possible configuration. The current study is not intended to be a sufficient measure of the adequacy of the ESA, and it does not eliminate the need for validation against case histories, however, it is able to offer insights into the problem, particularly in regard to verifying the ESA procedure against an independent set of analyses to identify a range of conditions where reasonable results can be expected, and identifying some key issues issues that may impact practical applications of the ESA in bridge abutment foundation design and analysis. 


\section{FOUNDATION PINNING AND CONSIDERED CONDITIONS}

Before describing the model development and results, it is important define a few important terms and the applicable conditions addressed by the current study to establish the expected applicability of the results and aid in the interpretation of the discussion and findings. In regard to the applicable conditions, this study considers only the case of a bridge abutment foundation with a finite-width approach embankment and makes no consideration for the foundations of interior bents that are not near a finite-width embankment. Of particular interest in this study are the relative responses of the 3D FEA and ESA models to changes in the width of the embankment for different depths and thicknesses of the liquefied layer. These responses are evaluated in regard to foundation pinning, which is defined in this study as the reduction in near-field lateral spreading displacement (i.e. soil near the foundation) relative to the displacement in the free-field (i.e. far from the foundation). The near-field reduction or degree of foundation pinning refer to quantifications of the magnitude of the near-field displacement relative to the free-field. For example, a case where the nearfield displacements that develop are quite small compared to the free-field displacements is referred to as having a large near-field reduction or a large degree of foundation pinning resistance, and a case where the magnitudes of the near-field and free-field displacements are similar is referred to as having a minimal degree of pinning resistance.

The term compatible displacement is also used throughout this discussion to indicate the expected near-field displacements for a given soil profile and foundation case. In the context of the 3D FEA, the displacement at the top of the foundation is essentially compatible with the near-field soil displacements and is taken as the compatible displacement. For the ESA, the compatible displacement is the displacement where the results of the BNWF and slope stability/deformation phases are in agreement (the process of finding this compatibility point is described in greater detail in subsequent sections). Ultimately, a bridge foundation designer addressing lateral spreading will want to estimate the expected foundation displacement, the corresponding structural demands imposed on the foundation, and 
other things such as the expected amount of foundation rotation or embankment settlement. These quantities are all related to the near-field soil displacement that develops under lateral spreading (McGann and Arduino, 2014, 2015; Ghofrani et al., 2016; Qiu et al., 2020), which motivates the use of the compatible displacement and the degree of foundation pinning as the primary assessment and comparative tools in the current study. Due to some simplifying assumptions made in this study, some of the complexity of the problem is lost, however, the focus is on the relative performance of the two analysis types and consistent assumptions are applied across all analyses to facilitate direct comparisons.

\section{D FINITE ELEMENT MODEL DEVELOPMENT}

All of the 3D finite element (FE) models consider the generic simplified scenario of a single deep foundation embedded in an idealized soil profile overlain by an approach embankment as depicted in Fig. 1. This generic site and model layout is intended to be the most simple representation of the problem that captures all of the relevant 3D effects. It is important to note that because the embankment extends fully across the mesh in the loading direction, static shear stresses due to a sloping embankment in front of the foundation are not considered in the 3D FEA. This approximation is adopted to facilitate comparisons to the BNWF analyses of the ESA procedure, which do not consider static shear stresses, and based on observations from sensitivity studies that indicated the static shear stresses do not significantly modify the trends observed in this set of 3D models.

The idealized soil profile adopted in this study consists of a deeper dense sand layer and a shallower loose sand layer that is effectively divided into two sublayers by the presence of the groundwater table, which is assumed to occur within the loose sand layer in all cases. All soils below the water table are assumed to be fully saturated, and the properties of the loose sand layer are assigned such that the saturated portion of the layer is highly susceptible to liquefaction. In subsequent discussion, the dry and saturated loose sand layers are typically referred to as the non-liquefiable crust and the liquefiable (or liquefied) layers, respectively. All of the 3D FEA and simplified ESA models are developed based on this idealized soil 
profile for all considered parameter combinations as discussed in subsequent sections.

\section{Soil Modeling}

The 3D FEA are developed and analysed using the OpenSees computational framework (McKenna et al., 2010; McKenna, 2011). Generic soil properties are assumed for the various soil layers in the model and listed in Table 1. Four layers are defined: the embankment fill, a dry crustal sand layer, a liquefiable saturated loose sand layer, and an underlying denser sand layer. The nested yield surface constitutive models of Elgamal et al. (2003) are used to model the material response of all considered soils in the 3D FEA. The embankment fill, crust, and dense sand layers are modeled with a Drucker-Prager type failure surface model that considers confining pressure-dependent strength (PDMY02). These layers are defined with the total mass densities, $\rho$, friction angles, $\phi$, and small strain shear and bulk moduli, $G_{\max }$ and $K_{\max }$, respectively, listed in Table 1. Stabilized single-integration point elements (McGann et al., 2015) were used to model all soil layers in the 3D FEA, and the beam-solid contact element of Petek (2006) is used to represent the soil-foundation interface.

Following the approach used by McGann and Arduino (2015), the development of liquefaction under seismic excitation and the subsequent development of lateral spreading is not modeled in the 3D FEA. Instead, it is assumed from the onset of the analysis that the material most susceptible to liquefaction has fully liquefied, and the kinematic demands of lateral spreading are introduced through an imposed displacement profile on the boundaries of the mesh. To this purpose, the liquefied loose sand layer is modeled as a pressure-independent material with a residual undrained strength, $S_{u}$, determined based on the recommendations of Ledezma and Bray (2010). This approach cannot capture complexities related to the development and initiation of liquefaction, for example how soil-structure interaction affects the build-up and dissipation of excess pore pressure (e.g., Elgmal et al., 2009; Li et al., 2019), however, the adopted method for imposing the kinematic demands of lateral spreading on the deep foundation not only simplifies the 3D analyses, it ensures that the desired free-field lateral spreading displacements are applied consistently across all cases and corresponds di- 
rectly with the approach used in both the BNWF and slope deformation phases of the ESA procedure, thus facilitating direct comparisons across the two modeling approaches.

\section{Boundary and Loading Conditions}

The mesh for each 3D FE model is generated to minimise boundary effects on the soilfoundation interface. In order to increase the mesh resolution while maintaining computational efficiency, symmetry conditions are used as shown in Fig. 1 where only one half of the system is considered. Note that due to these symmetry conditions the $4 \mathrm{~m}$ wide embankment crest for the example mesh shown is represented by a $2 \mathrm{~m}$ wide half-embankment. Boundary conditions are applied by fixing out-of-plane translation at the nodes on all edges of the mesh excepting the ground surface. The base node of the deep foundation is fixed against vertical translation, and the uppermost node is fixed against all rotations to simulate a condition similar to the rotational restraint that would be provided by a pile cap or abutment in a real bridge foundation. This rotational fixity does not capture all of the complexity associated with the pile cap, abutment, or expansion gap that would influence the rotational response at the top of a bridge foundation, but it is chosen for the current study as the more applicable of the two simplified rotational conditions (i.e. fixed or free) available for a single foundation. All deep foundation nodes are fixed against translation perpendicular to the symmetry plane and are only allowed rotations within the symmetry plane. No installation effects are considered in the model set-up or analysis as these effects are beyond the scope of the current simplified analyses.

Body forces are applied to the solid elements in order to achieve an appropriate initial state of stress in the soil prior to any subsequent analysis. The kinematic demands of lateral spreading are simulated by incrementally imposing displacements to the non-symmetry vertical mesh boundaries. These boundaries are indicated in red on the plan view of the $x-y$ plane in Fig. 1. A simplified displacement profile is chosen for this purpose, with constant displacement above the liquefied layer, zero displacement below the liquefied layer, and a linearly-varying displacement through the liquefied layer. Fig. 1 shows the form of the 
adopted displacement profile in the context of the overall FE mesh in the $x$ - $z$ plane elevation view. Note that this is applied to all three of the boundaries indicated in the plan view rather than just on the boundary shown in the elevation view. The final free-field surface displacement for all 3D FE models is taken as $1 \mathrm{~m}$. While simple, the adopted displacement profile captures the most important aspects of the problem (i.e. lateral movement of crust above a liquefied layer) and is sufficient for the purposes of this study. Additionally, the same simple displacement profile is used in the BNWF phase of the ESA to facilitate comparisons across the two analysis types. Further details on the loading conditions are available in McGann and Arduino (2015).

\section{Deep Foundation Models}

Two deep foundation models are considered, one with a $0.6 \mathrm{~m}$ diameter and one with a $1.4 \mathrm{~m}$ diameter. These foundation models are based on actual circular reinforced concrete cross-sectional designs, and consider linear elastic behaviour only. The material and section properties used to define the deep foundation models are provided in Table 2. The elastic modulus, $E$, values are chosen such that the linear elastic bending stiffness, $E I$, corresponds to the initial cracked bending stiffness of the nonlinear moment curvature responses of the template cross-sections. The cross-section area, $A$, and second area moment, $I$, values reported in Table 2 are based on one-half of the cross-section for consistency with the symmetry conditions assumed in the 3D FEA. The full values of $A$ and $I$ are used in the BNWF phase of the ESA models, as no corresponding symmetry condition is applicable. Standard elastic beam column elements are used to model the deep foundations in both the 3D FEA and BNWF analyses. Further details on the template cross-sectional designs used to define these models are discussed in McGann et al. (2012).

The use of single deep foundations and linear elastic foundation response are important simplifications adopted in the current study in an effort to keep the models as simple as possible while still capturing the core aspects of the laterally-loaded deep foundation problem. It is important to note that the models considered here are simplified representations of bridge 
abutment foundations with finite-width approach embankments where group foundations are typical, rather than representations of the foundations for interior bents. Simplifying this problem down to a single foundation instead of using a group means that the analyses cannot capture complexities of the soil-foundation-abutment system response related to group effects and the rotational restraint of the grouped foundation (among others), however, because the focus of the study is on the comparison between the 3D FEA and the ESA and both sets of

analyses are based on the same simplifying assumption of a single foundation, meaningful observations can still be drawn from the relative results. The use of linear elastic deep foundation response is similarly motivated. Nonlinear foundation response is important to the overall system response during lateral spreading (e.g., McGann and Arduino, 2015; Ghofrani et al., 2016; Qiu et al., 2020) and the current models cannot capture any effects related to such response, but both the 3D FEA and the BNWF analyses in the ESA approach use the same linear elastic foundations, and observations drawn from comparisons of the two approaches are still able to reveal insights into the performance of the ESA under different conditions.

\section{EQUIVALENT STATIC ANALYSIS MODEL DEVELOPMENT}

The recommendations of Ashford et al. (2011) are used to develop ESA models for the same set of cases as the 3D FEA. The BNWF models are also developed and analyzed using OpenSees. These models use elastic beam-column elements to represent the deep foundation with the properties shown in Table 2 and $p$ - $y$ springs are used to model the soil response. The $p$ - $y$ springs are modeled using zero-length elements and the uniaxial constitutive model implemented in OpenSees after Boulanger et al. (2003). The method of Brinch Hansen (1961) is used to compute the ultimate strength values for the $p-y$ springs using the properties in Table 1, as previous work by McGann et al. (2011) found that p-y springs with ultimate strengths defined using this approach compared best to $p-y$ curves computed from 3D FE models similar to those in the current study. The $p$ - $y$ springs in the liquefied layer adopt a soft clay type backbone curve similar to that proposed by Matlock (1970) based on the $S_{u}$ 
value of Table 1 . The remaining layers adopt a sand type backbone curve similar in shape to the API (2007) hyperbolic tangent function. Initial stiffness values are assigned using the API (2007) approach corrected for overburden pressure as recommended by Boulanger et al. (2003). A linearly varying reduction in ultimate lateral strength is applied to the $p$ - $y$ springs within one pile diameter of the liquefied layer as recommended by Ashford et al. (2011) to account for soft layer interaction effects. The BNWF models are analyzed by applying a set displacement profile to the soil end of the $p-y$ springs in accordance with the standard ESA approach. The displacement profile used for this purpose corresponds exactly with that used in the 3D FEA, though a maximum value of $2 \mathrm{~m}$ is applied in the BNWF models to ensure adequate near-field deformation.

The slope stability models for the ESA procedure are developed using the same generic site layout shown in Fig. 1, though these models do not explicitly model the foundation. These models are developed using SLOPE/W (GEO-SLOPE, 2016) and the circular failure surface method of Spencer (1967) is used for all limit equilibrium calculations. Fig. 2 shows the general layout used for these models along with a couple of example failure surfaces. The failure surfaces are limited such that the failure mass cannot extend back away from the edge of the embankment by more than four times the embankment thickness in accordance with the recommendations of Boulanger et al. (2006) and Ashford et al. (2011), but no other restrictions are applied. Note that the slope shown in Fig. 2 is not the side slope that is considered in the 3D FEA and shown in Fig. 1, but is instead the slope that would exist in front of a hypothetical abutment if this analysis considered a real bridge foundation. This slope is assigned the same 2:1 gradient that is applied to the side slopes.

The properties for the slope stability phase of the ESA correspond directly with those used in the 3D FEA and listed in Table 1, and the same residual strength approach is applied to the liquefied layer in order to assess the stability of the system in a liquefied state. The nonliquefiable layers are modeled using a Mohr-Coulomb failure surface and the liquefied layer is modeled as an undrained material with an $S_{u} / \sigma_{v}$ ratio of 0.1 and a minimum undrained 
strength of $5 \mathrm{kPa}$ to correspond with the 3D FEA. The foundation resisting force is applied in the models as a reinforcement line, such that the specified resisting force is applied along the edge of the failure surface wherever it intersection the location of the foundation. For the majority of cases, this occurs between the middle and bottom of the liquefied layer, but no restriction is imposed in the models to force this to occur. As discussed by Armstrong et al. (2014), this modeling decision neglects any additional resistance coming from the internal bending moment in the foundation, however, because the moment is close to zero near the middle of the liquefied layer this is a reasonable simplification.

The slope stability models are used to determine the horizontal yield accelerations causing $\mathrm{FS}=1$ using the standard pseudostatic seismic slope stability approach for a series of seven foundation resisting forces $(0,50,100,200,400,800$, and $1600 \mathrm{kN})$ for each of the considered soil profiles. The size of the failure mass is allowed to increase with increasing foundation resisting force, but the maximum distance between the foundation and the edge of the failure mass is limited to four times the embankment thickness based on the recommendations of Ashford et al. (2011). The expected level of deformation is determined for each yield acceleration using the rigid Newmark sliding block regression equation of Bray and Travasarou (2007). To examine the effects of ground motion intensity on the results of the ESA procedure, a series of ground motions collated by Tarbali and Bradley (2014) is used to establish 120 pairs of PGA and $M_{w}$ that are applied to the Bray and Travasarou (2007) equation to estimate deformations for each yield acceleration.

\section{CONSIDERED SITE GEOMETRIES}

The generic site layout and properties discussed in the preceding sections are used to examine the effects of different site geometries on the soil-foundation system response to lateral spreading through the consideration of a large number of different geometric combinations. The geometric aspects varied to create the matrix of considered cases are the embankment crest width, $w$, the thickness of the crust layer (dry loose sand layer), $z$, the thickness of the liquefiable layer (saturated loose sand layer), $t$, and the diameter of the deep foundation, 
d. The current study is an expansion of the work of McGann and Arduino (2015), where 72 distinct geometric combinations were considered in 3D FEA: three crustal thicknesses $(z=1.0,3.0,6.0 \mathrm{~m})$, three liquefiable layer thicknesses $(t=1.0,3.0,6.0 \mathrm{~m})$, four embankment crest widths ( $w=4.0,8.0,16.0 \mathrm{~m}$ and full model width), and two foundation diameters $(d=0.6$ and $1.4 \mathrm{~m})$. McGann and Arduino (2015) identified several shortcomings in the case matrix for the original parameter study, in particular with regard to the lack of more realistic crustal and liquefiable layer thickness. To expand upon this previous effort, two new crustal thicknesses $(z=1.5$ and $2 \mathrm{~m})$ and two new liquefiable layer thicknesses $(t=2$ and $4 \mathrm{~m})$ are added to the case matrix, resulting in 128 distinct new cases. When combined with the 72 cases and results of McGann and Arduino (2015), this provides a total of 200 distinct geometric combinations that are analyzed using 3D FEA and the ESA procedure.

Figure 3 shows a summary of the soil profiles and embankment geometries considered in the overall case matrix. This plot does not show all of the considered combinations, but is intended to portray the different parameter variations in relative terms. Of particular note are the embankment widths. Three of the embankment cases are representative of varying sizes of finite-width embankments for which a larger degree of foundation pinning is expected. These embankments are distinguished by the crest widths and are defined with 2H:1V side slopes. The fourth case considers an embankment that extends across the entire model domain and for which significant foundation pinning effects are not expected. This fourth case is only considered in the 3D FEA, and is used to evaluate the relative degree of foundation pinning for each of the other embankment width cases based on the reduction in near-field deformation relative to that in the corresponding full-width case.

\section{D FINITE ELEMENT ANALYSIS RESULTS}

The effects of approach embankment and soil profile geometry on the flexural response of the foundations in the 3D FEA are initially assessed through comparisons of the results obtained from the various cases considered in the parameter study. In general, the results of 
the 3D FE parameter study demonstrate that the presence of the deep foundation alters the near-field soil deformations such that only the material near the boundaries experiences the full free-field displacement applied to the models. The level of resistance varies significantly with changes in embankment width, crust thickness, and foundation stiffness. Changes in liquefied layer thickness are less significant, however there is a reduction in peak foundation shear force and bending moment demand with increasing thickness of liquefiable soil. These reductions are relatively modest for the for liquefied layers $\leq 3 \mathrm{~m}$ thick and more pronounced for the 4 and $5 \mathrm{~m}$ thick layers.

To demonstrate the range of responses obtained from the 3D FEA, and to provide an overall sense of the model results and performance, Fig. 4 shows the deformed mesh with contours of displacement in the loading direction (to the right in the figure) for section and plan views of two models that differ only in terms of embankment width. Fig. 4(a) shows a case with an $4 \mathrm{~m}$ wide embankment, and Fig. 4(b) shows a case with a $16 \mathrm{~m}$ wide embankment. As indicated by a comparison of Figs. 4(a) and (b), for constant soil profile and foundation parameters, the presence of a wider embankment significantly alters the degree of foundation pinning resistance in the 3D models. For the narrower $4 \mathrm{~m}$ wide embankment case, the foundation provides substantial resistance to the lateral deformation of the soil and near-field soil deformations are approximately one-quarter of the free-field. This effect is manifested over a large portion of the soil domain that extends well beyond the near-field soil surrounding the foundation. In contrast, in the $16 \mathrm{~m}$ wide embankment case shown in Fig. 4(b), the foundation offers a relatively smaller degree of pinning resistance, as the nearfield soil displacements are approximately $60 \%$ of the free-field displacements and a larger zone of soil experiences displacements closer to the free-field values.

The overall results of the 3D FEA parameter study are summarized in Fig. 5, which shows the foundation bending demand profiles (displacement, shear force, and bending moment) for the indicated soil profile parameter combinations for the $0.6 \mathrm{~m}$ diameter foundation models after the full application of the $1 \mathrm{~m}$ free-field displacement profile. In these plots, $w 1$ through 
$w_{4}$ refer to the four embankment crest widths ordered from low to high $(4 \mathrm{~m}, 8 \mathrm{~m}, 16 \mathrm{~m}$, and full model width), while the thickness of the liquefiable layer $(t=1,2,3,4$, and $6 \mathrm{~m})$ and non-liquefiable crust $(z=1,1.5,2,3$, and $6 \mathrm{~m})$ are noted for each row and column. The results of Fig. 5 further demonstrate that increased embankment width leads to increased foundation bending demands and displacements, and indicate that this applies both in terms of the maximum demands as well as in terms of the overall demand profiles.

Embankment width is not the only critical factor in the system response for these models, as the crust thickness and foundation size/stiffness play an important role in defining how changes in embankment width affect the foundation and the degree of pinning resistance. For the cases with crust thicknesses $z \leq 2 \mathrm{~m}$, the approach embankment is the primary source of kinematic demands on the foundation during lateral spreading and differences in the 3D geometry of the embankment can significantly influence the system response. As the crust thickness is increased in the $z=3$ and $6 \mathrm{~m}$ cases, the kinematic demands placed upon the foundation by the lateral movement of the crust layer begin to control the overall system response and any differences in 3D embankment geometry become less significant. This effect is at least partially due to the method used to simulate the lateral spreading demands in the 3D models, as the assumption of constant free-field displacement above the liquefied layer becomes less sound with increasing crust thickness, but the diminishing influence of 3D embankment geometry on the foundation response with increasing depth to the liquefied layer makes physical sense.

These observations suggest that for these single deep foundation cases, there is a limiting crustal thickness at which 3D embankment effects are no longer a significant factor in defining the foundation demands during lateral spreading. Based on the results of Fig. 5, the limiting crustal thickness is somewhere between 3 and $6 \mathrm{~m}$. The trends for the $1.4 \mathrm{~m}$ diameter foundation (not shown here) mirror those shown in Fig. 5, however, as with all soil-structure interaction problems for deep foundations, the relative soil-foundation stiffness influences the system response. For all cases, the $1.4 \mathrm{~m}$ foundation undergoes less deformation for the same 
free-field displacement and the foundation response is less affected for corresponding increases in embankment width and crust thickness. Despite the differences in system response, the results for the $1.4 \mathrm{~m}$ foundation also indicate that the limiting crust thickness beyond which 3D embankment effects are minimally influential on the degree of foundation pinning is between 3-6 $\mathrm{m}$. The embankment thickness is set at $5 \mathrm{~m}$ in all models, and a reasonable inference from these results suggests that a significant degree foundation pinning should not be expected for bridge abutment foundations at sites with crust thicknesses greater than or equal to the embankment thickness regardless of the width of the embankment. This limiting thickness is almost certainly a function of the relative soil-foundation stiffness ratio, so this observation should not be applied directly to the analysis of grouped foundations, but instead can be interpreted as guidance for the expected behaviour that may develop for conditions that are not considered in the current study.

\section{EQUIVALENT STATIC ANALYSIS RESULTS}

The foundation pinning compatible surface lateral spreading displacements are found from the ESA procedure by plotting the force-displacement curves obtained from the BNWF and slope stability/deformation phases and finding the displacement at the intersection points of the curves. This is done for all 25 distinct soil profiles ( 5 crust thicknesses and 5 liquefied layer thicknesses) and for both foundation cases. Fig. 6 shows the compatible displacement determination process for the cases with a $2 \mathrm{~m}$ thick crust and the $0.6 \mathrm{~m}$ diameter deep foundation. The trends of increasing compatible displacement with both increasing liquefied layer thickness and increasing embankment width are typical of the trends displayed in all cases.

Two modifications to the raw computed data are made in order to better consider the behaviour of the system. The first modification is related to the consideration for the embankment width, as the BNWF and slope stability/deformation analyses cannot explicitly consider changes in the embankment width. In order to consider the effect of this parameter in the analyses, the results from the slope stability/deformation analyses, in which the forces 
are computed on a per-unit-thickness basis, are multiplied by the three tributary embankment widths. In accordance with Boulanger et al. (2006), the tributary embankment widths used for this purpose are taken as the crest width plus one half of the material on the side slopes. For the $2 \mathrm{H}: 1 \mathrm{~V}$ slope and $5 \mathrm{~m}$ height assumed in this study, the tributary widths are 9, 13 , and $21 \mathrm{~m}$ for the 4,8 , and $16 \mathrm{~m}$ crest widths, respectively.

The second modification is related to the foundation restraining force used in the BNWF pushover curves. To account for the incompatibility in how the foundation shear force is considered in each analysis phase of the ESA procedure (i.e. shear forces increase with increasing deformation in the BNWF analyses, but are constant in a given the slope stability/deformation analysis), the BNWF pushover curves used to determine compatible displacements are based on the equivalent constant restraining force concept developed by Boulanger et al. (2006). The equivalent constant restraining force is calculated as the average foundation shear force $V_{\text {avg }}$ developed at the center of the liquefiable layer as the displacement increases from zero. At a given load step $n$, this is computed as

$$
V_{\mathrm{avg}}(n)=\frac{\sum_{i=1}^{n} V(i)}{n}
$$

where $V(i)$ is the shear force computed in the BNWF model at each load step $i$. Using this approach, the pushover curves are developed by plotting the displacement at the top of the foundation against $V_{\text {avg }}$ at the center of the liquefied layer for each case. While the failure surfaces in the slope stability analyses need not pass through the center of the liquefied layer, the shear force at this point is used as there is little variation in shear through the liquefied layer (e.g. Fig. 5). It is important to note that Eq. 1 requires the use of constant increments in the pushover analysis. If non-uniform increments are used, then this equation will return an equivalent constant restraining force that is disproportionally weighted and may have significantly smaller shear forces than is appropriate. It is recommended that uniformly-sized increments are used, but if non-uniform increments are used then Eq. 1 should be replaced 
with a weighted average when determining the equivalent constant restraining force.

Figs. 7 and 8 summarize the results for all 150 geometric configurations and 120 ground motions $\left(M_{w}\right.$ and PGA pairs) considered in the ESA study. Though there is some scatter in the results, the expected trends of increasing compatible displacement with increasing PGA and increasing embankment width are present in the results for both foundation cases. Also as expected, the compatible displacements for the $1.4 \mathrm{~m}$ diameter foundation are smaller than for the $0.6 \mathrm{~m}$ foundation, with the results in Fig. 7 being about 4 times greater than the corresponding results in Fig. 8. These observations confirm that the ESA procedure is appropriately considering the effects of ground motion intensity, embankment width, and relative soil-foundation stiffness, or at least confirming that changes in these parameters produce predictable changes in the ESA results.

\section{Variation with Liquefied Layer and Crust Thickness}

Figs. 7 and 8 indicate two other trends that warrant discussion, as they differ from the trends indicated in the 3D FEA results. Firstly, there is a distinct trend of increasing compatible displacement with increasing liquefied layer thickness that is not observed in the results of the 3D FEA. Secondly, there is a general trend of decreasing compatible displacement with increasing crust thickness regardless of PGA that is opposite to the trend indicated in the 3D FEA. In regard to the former observation, the 3D FEA results of Fig. 5 indicate that liquefied layer thickness affects the magnitude of the internal shear and moment, but has minimal effect on the surface displacement of the foundation. The trend evident in the ESA results is driven by two sources. In the BNWF analyses, increasing the thickness of the liquefied layer serves to decrease the shear force demand within the liquefied layer (much as is shown in Fig. 5). As previously discussed, the compatible displacement determination (e.g. Fig. 6) is carried out by plotting the BNWF pushover results in terms of the running average shear force at the center of the liquefied layer. Decreasing the magnitude of this shear force directly decreases the magnitude of the pushover curve, and due to the typical form of the slope stability/deformation curves, this results in an increase in compatible displacement. 
The slope stability/deformation analyses further contributes to increasing the compatible displacement, as increasing the thickness of liquefied soil decreases the stability of the system, leading to lower yield accelerations and correspondingly greater deformations returned by the Newmark sliding block analysis for a given ground motion intensity. Though the trends indicated in the 3D FEA and ESA for increasing liquefied layer thickness disagree, it is not necessarily problematic to practical applications of the ESA approach as it will lead to more conservative results for soil profiles with larger zones of soil that are highly susceptible to liquefaction where greater free-field lateral spreading displacements would be expected.

\section{Free-field Deformation Proxy and Foundation Pinning Resistance Ratio}

The trend in the ESA results of decreasing compatible displacement with increasing crust thickness indicated in Figs. 7(c) and 8(c) requires further context to evaluate, particularly because the ESA results have no inherent benchmark with which to gauge the degree of foundation pinning resistance represented by the compatible displacements. To provide this context, the lateral displacement index (LDI) of Zhang et al. (2004) is used as a proxy for the expected free-field lateral spreading deformation and compared to the compatible displacements. Representative uncorrected SPT blowcount values of 7.5 and 36 are assumed for the loose and dense sand layers based on the relative density implied by the elastic parameters of Table 1. The procedure of Idriss and Boulanger (2008) is used to determine corresponding maximum shear strain profiles for for each combination of soil profile and ground motion intensity, which are then integrated to determine LDI values. The embankment and foundation are not included in these calculations such that the LDI values are representative estimates of the free-field lateral spreading displacements.

Fig. 9 shows the variation with PGA for the LDI values computed for all 25 soil profiles and 120 ground motion intensities with the marker colors indicating the thickness of the liquefied layer or non-liquefiable crust. As shown, there is an expected trend of increasing LDI with increasing liquefied layer thickness that corresponds to the trend observed in the compatible displacements. There is also a general trend of increasing LDI with increasing 
crust thickness that runs counter to the observations of Figs. 7(c) and 8(c) and indicates that the degree of foundation pinning resistance in the ESA procedure is substantially larger for soil profiles with thicker crusts. Fig. 10 summarizes this effect by plotting the compatible displacements, LDI, and reduction ratios for the $0.6 \mathrm{~m}$ diameter foundation cases. In this context, the reduction ratio is taken as the ratio of the compatible displacement to the corresponding LDI value such that a small reduction ratio indicates significant degree of pinning resistance while values close to unity indicate a minimal degree of pinning resistance.

The reduction ratios of Fig. 10 indicate a clear trend of increasing degree of pinning resistance with increasing crust thickness that is also observed in the corresponding results for the $1.4 \mathrm{~m}$ diameter foundation cases (not shown here). Though the LDI values are not necessarily expected to be a perfect prediction of the actual free-field lateral spreading displacements (e.g., Russell et al., 2017), the trends in the results can be used more reliably due to the way the empirical prediction functions are developed. The observation that the compatible displacements returned by the ESA display the opposite trend with changes in crust thickness relative to the expected free-field displacements is significant, as underprediction of the compatible displacement could lead to unconservative design solutions. It is also noted that the trend in the ESA compatible displacements to decrease with increasing crust thickness is also opposite to the trend found in the 3D FEA. This comparison is discussed further in the next section.

\section{Comparison to $3 \mathrm{D}$ FEA}

Comparison to the 3D FEA results provides further confirmation of the previously identified trends in the ESA results. To this purpose, the pile head displacements developed at the end of the 3D analyses are interpreted as the 3D FEA compatible displacements, as they represent the response of the soil-pile system to the kinematic demands of lateral spreading imposed in the 3D models. Due to the incompatibility between the free-field displacements in the 3D FEA and ESA studies (i.e., imposed $1 \mathrm{~m}$ free-field displacement for all cases in 3D, deformations dependent on ground motion intensity in ESA), comparison across all of 
the cases is not applicable. However, comparisons to the subset of the ESA results where the LDI is nearly $1 \mathrm{~m}$ ensures compatibility in the expected free-field displacements between the two analysis methods, providing a more appropriate means of comparison. Though all of the models are developed for the same soil profiles and conditions, differences in how the two analysis types model the soil and the soil-foundation interface will affect the results and lead to differences between the two approaches, however, these differences should not affect the overall trends in the data to a significant degree.

Fig. 11 compares the compatible displacements returned from the ESA with the pile head displacement at the end of the 3D FEA for only the subset of ESA cases where the LDI is between 95-105 cm. These parameters are chosen for comparison as the compatible displacement represents the magnitude of expected foundation deformation in the ESA procedure for the cases where the free-field displacement proxy, LDI, is nearly $1 \mathrm{~m}$, while the pile head displacement at the end of the 3D analyses is the maximum foundation deformation under the applied $1 \mathrm{~m}$ free-field displacement in the 3D FEA cases.

The two analysis types display corresponding trends in terms of changes in embankment width and opposite trends in terms of changes in crust thickness. The trends with changes in liquefied layer thickness (not shown in Fig. 11) also disagree between the two analysis types, but as previously discussed, these differences are not overly problematic. The two analysis types show corresponding trends in terms of changes in foundation size/stiffness. Given all else equal, the $1.4 \mathrm{~m}$ diameter foundation models return smaller foundation deformations than the $0.6 \mathrm{~m}$ cases for both the ESA and 3D FEA, though the decrease in compatible displacement is larger in the ESA relative to the 3D FEA. In this case, this difference the degree of change across the two sets of results is attributed to the differences in how the BNWF and 3D FE analyses model the soil-foundation system for this set of soil and pile properties, and not any particular flaw or issue in either type of analysis.

The difference in behavior with changes in crust thickness remains problematic. From a physical perspective, given a certain magnitude of free-field lateral spreading deformation, 
a thicker crust would impose larger forces on an embedded foundation and cause the development of larger near-field deformations than a thin crust layer. This physical response is reflected in the 3D FEA results of Fig. 11, but the ESA results indicate that expected nearfield deformation reduces significantly for larger crusts. Based on the results of Figs. 11(a) and (b), it appears that the limiting crust thickness is $2 \mathrm{~m}$ for the $0.6 \mathrm{~m}$ diameter foundation. For crusts $<2 \mathrm{~m}$ thick, the ESA and 3D FEA predict similar and reasonable amounts of foundation pinning resistance, while for crust thicknesses $\geq 2 \mathrm{~m}$, the ESA results indicate a significantly greater degree of pinning resistance than is evident in the 3D FEA.

\section{CONCLUSIONS}

A large parametric analysis was carried out using 3D FEA and a simplified ESA procedure to investigate the effects of embankment width, crust thickness, liquefiable layer thickness, and foundation size/stiffness on the expected level of foundation pinning resistance for piled bridge abutment foundations with finite-width approach embankments subject to liquefaction-induced lateral spreading. These analyses considered a single deep foundation embedded in a simple soil profile and made consideration for 2 foundation cases, 25 soil profiles, 3 embankment widths, and 120 ground motion intensities in the ESA procedure. It was found that both analysis types displayed corresponding and expected trends of decreasing degree of foundation pinning resistance (as defined as ratio of near-field to free-field displacement) with increasing approach embankment width. The trends with increasing liquefiable layer thickness differed, with the 3D FEA showing little effect and the ESA showing a decrease in foundation pinning resistance, however, practical applications of the ESA procedure should remain conservative in this regard as increasing liquefiable layer thickness will typically lead to greater free-field lateral spreading displacements. Comparisons of the ESA and 3D FEA results also displayed a difference in sensitivity to changes in foundation size/stiffness, but this observation is inconclusive due to some of the simplifying assumptions in this study, and further research is required to better understand this effect.

The primary and most significant difference between the two analysis types was related 
to the effect of changes in non-liquefiable crust thickness on the degree of foundation pinning resistance. Where the 3D FEA results indicate a trend of decreasing degree of pinning resistance with increasing crust thickness that seems to agree with the physics of the problem, the ESA results indicate the opposite trend. This is driven by a combination of the BNWF and slope stability/deformation phases of the ESA approach, but while the BNWF behaviour of increasing the mobilised shear force in the foundation with increasing crust thickness is grounded in the mechanics of the problem, the effects of the slope stability/deformation phase seem to be at least partially related to the inapplicability of this type of analysis to lateral spreading. Due to the greatly reduced shear strength in the liquefied layer relative to the adjacent layers, the failure surfaces in the slope stability analyses all pass through the liquefied layer, typically crossing the location of the piles somewhere between the middle and bottom of the layer (though this is not strictly enforced in the analyses). Increasing the mobilised resisting force where the failure surface intersects the foundation will naturally reduce the estimated deformation. However, there is a second effect that occurs with increasing crust thickness, as the proportion of competent soil along the failure surface increases, leading to much larger reductions in expected slope deformation than would be indicated by the larger mobilised foundation resistance alone. Caution is recommended for practical applications of this procedure for sites with nonliquefiable crusts thicker than 3-4 m below an embankment as the ESA procedure may return compatible displacements associated with an unconservatively large degree of foundation pinning resistance.

Beyond just this issue, the slope stability/deformation phase of the ESA procedure seems to be its most problematic aspect for several reasons. Firstly, the phenomenon of lateral spreading is not particularly well-represented as a conventional limit equilibrium stability problem. Secondly, there is a fair bit of uncertainty involved in use of any Newmark sliding block method to estimate deformations from the critical yield accelerations returned in the slope stability analyses, and the Bray and Travasarou (2007) procedure used in the current study is not intended to be used for lateral spreading and is only applicable to to slopes with 
materials that do not undergo liquefaction or other significant strength loss during seismic shaking. The Newmark approach was selected in the current study the absence of a better alternative, and with the exception of complex nonlinear effective stress analyses that have their own issues for predicting lateral spreading response, this approach likely remains the best choice in the context of a simplified procedure. Due to the inherent limitations of the ESA procedure, best practice should consider a range of input conditions and upper/lower bound estimates of response in order to guide the design decision making process, and it may be useful to supplement the ESA with more complex analyses for sites with greater consequences of lateral spreading damage.

\section{DATA AVAILABILITY}

All data, models, and code generated and used during this study are available from the corresponding author by request.

\section{ACKNOWLEDGEMENTS}

The commercial pre- and post-processing software GiD (CIMNE, 2008) was used to support model generation and visualize results for the 3D FEA. The seismic slope stability models from the ESA procedure were developed and analysed using SLOPE/W (GEOSLOPE, 2016). Funding for this work was provided by PacTrans, the Regional University Transportation Center for US Federal Region 10, and QuakeCoRE, a New Zealand Tertiary Education Commission-funded Centre. This is QuakeCoRE publication number 0461.

\section{REFERENCES}

American Petroleum Institute (API) (2007). Recommended Practice for Planning, Designing and Constructing Fixed Offshore Platforms-Working Stress Design. API Recommended Practice 2A-WSD (RP 2A-WSD), 21st edition. Errata and Supplement 3, October 2007.

Armstrong, R. J., Boulanger, R. W., and Beaty, M. H. (2014). "Equivalent static analysis of piled bridge abutments affected by earthquake-induced liquefaction." Jour- 
nal of Geotechnical and Geoenvironmental Engineering, ASCE, 140(8), 04014046. doi: 10.1061/(ASCE)GT.1943-5606.0001152.

Ashford, S. A., Boulanger, R. W., and Brandenberg, S. J. (2011). "Recommended design practice for pile foundations in laterally spreading ground." PEER Report No. 2011/04, Pacific Earthquake Engineering Research Center, University of California, Berkeley.

Berrill, J. B., Christensen, S. A., Keenan, R. P., Okada, W., and Pettinga, J. R. (2001). "Case study of lateral spreading forces on a piled foundation." Géotechnique, 51(6), 501-517.

Boulanger, R. W., Chang, D., Gulerce, U., Brandenberg, S. J., and Kutter, B. L. (2006). "Evaluating pile pinning effects on abutments over liquefied ground." Seismic Performance and Simulation of Pile Foundations in Liquefied and Laterally Spreading Ground, R. W. Boulanger and K. Tokimatsu, eds., GSP 145, ASCE, 306-318.

Boulanger, R. W., Kutter, B. L., Brandenberg, S. J., Singh, P., and Chang, D. (2003). Pile Foundations in liquefied and laterally spreading ground during earthquakes: Centrifuge experiments and analyses. Center for Geotechnical Modeling, University of California at Davis, Davis, CA. Rep. UCD/CGM-03/01.

Bray, J. D. and Travasarou, T. (2007). "Simplified procedure for estimating earthquakeinduced deviatoric slope displacements." Journal of Geotechnical and Geoenvironmental Engineering, ASCE, 133(4), 381-392.

Brinch Hansen, J. (1961). "The ultimate resistance of rigid piles against transversal forces." Bulletin No. 12, Geoteknisk Institute, Copenhagen, 5-9.

CIMnE (2008). GiD The Personal Pre and Post Processor. International Center for Numerical Methods in Engineering (CIMNE).

Elgamal, A., Yang, Z., Parra, E., and Ragheb, A. (2003). "Modeling of cyclic mobility in saturated cohesionless soils." International Journal of Plasticity, 19, 883-905. 
Elgmal, A., Lu, J., and Forcellini, D. (2009). "Mitigation of liquefaction-induced lateral deformation in a sloping stratum: Three-dimensional numerical simulation." Journal of Geotechnical and Geoenvironmental Engineering, 135(11), 1672-1682. doi: 10.1061/(ASCE)GT.1943-5606.0000137.

GEO-SLOPE (2016). SLOPE/W. https://www.geo-slope.com/products/slope-w, Accessed March 2017.

Ghofrani, A., McGann, C. R., and Arduino, P. (2016). "Influence of modeling decisions on 3D finite element analysis of two existing highway bridges subjected to lateral spreading." Transportation Research Record: Journal of the Transportation Research Board No. 2592. doi: $10.3141 / 2592-16$.

Idriss, I. M. and Boulanger, R. W. (2008). Soil Liquefaction During Earthquakes. Earthquake Engineering Research Institute (EERI), MNO-12.

Ledezma, C. and Bray, J. D. (2010). "Probabilistic performance-based procedure to evaluate pile foundations at sites with liquefaction-induced lateral displacement." Journal of Geotechnical and Geoenvironmental Engineering, ASCE, 136(3), 464-476.

Ledezma, C., Hutchinson, T., Ashford, S. A., Moss, R., Arduino, P., Bray, J. D., Olson, S., Hashash, Y. M. A., Verdugo, R., Frost, D., Kayen, R., and Rollins, K. (2012). "Effects of ground failure on bridges, roads, and railroads." Earthquake Spectra, 28(S1), S119-S143.

Li, W., Stuedlein, A. W., Chen, Y., Liu, H., and Cheng, Z. (2019). "Response of pile groups with $\mathrm{X}$ and circular cross-sections subject to lateral spreading: 3D numerical simulations." Soil Dynamics and Earthquake Engineering, 126, 105774. doi: 10.1016/j.soildyn.2019.105774.

Martin, G. R., March, M. L., Anderson, D. G., Mayes, R. L., and Power, M. S. (2002). "Recommended design approach for liquefaction induced lateral spreads." Proc., 3rd Natl. Seismic Conf. and Workshop on Bridges and Highways, MCEER-02-SP04, Buffalo, NY. 
Matlock, H. (1970). "Correlations for design of laterally loaded piles in soft clay." Proceedings of the 2nd Offshore Technology Conference, Houston, TX, (OTC 1204), 577-594.

McGann, C. R. and Arduino, P. (2014). "Numerical assessment of three-dimensional foundation pinning effects during lateral spreading at the Mataquito River Bridge." Journal of Geotechnical and Geoenvironmental Engineering, ASCE, 140(8), 04014037. doi: 10.1061/(ASCE)GT.1943-5606.0001134.

McGann, C. R. and Arduino, P. (2015). "Numerical assessment of the influence of foundation pinning, deck resistance, and 3D site geometry on the response of bridge foundations to demands of liquefaction-induced lateral soil deformation." Soil Dynamics and Earthquake Engineering, 79, 379-390. doi: 10.1016/j.soildyn.2015.04.024.

McGann, C. R., Arduino, P., and Mackenzie-Helnwein, P. (2011). "Applicability of conventional $p-y$ relations to the analysis of piles in laterally spreading soil." Journal of Geotechnical and Geoenvironmental Engineering, ASCE, 137(6), 557-567.

McGann, C. R., Arduino, P., and Mackenzie-Helnwein, P. (2012). "Development of simplified analysis procedure for piles in laterally spreading layered soils." PEER Report No. 2012/05, Pacific Earthquake Engineering Research Center, University of California, Berkeley.

McGann, C. R., Arduino, P., and Mackenzie-Helnwein, P. (2015). "A stabilized singlepoint finite element formulation for three-dimensional dynamic analysis of saturated soils." Computers and Geotechnics, 66, 126-141. doi: 10.1016/j.compgeo.2015.01.002.

McKenna, F. (2011). "OpenSees: A framework for earthquake engineering simulation." Computing in Science and Engineering, 13(4), 58-66.

McKenna, F., Scott, M. H., and Fenves, G. L. (2010). "Nonlinear finite element analysis software architecture using object composition." Journal of Computing in Civil Engineering, 24(1), 95-107. 
Palermo, A., Liu, R., Rais, A., McHaffie, B., Andesheh, K., Pampanin, S., Gentile, R., Nuzzo, I., Granerio, M., Loporcaro, G., McGann, C. R., and Wotherspoon, L. M. (2017). "Performance of road bridges during the 14 November 2016 Kaikōura Earthquake." Bulletin of the New Zealand Society for Earthquake Engineering, 50(2), 253-270.

Petek, K. A. (2006). Development and Application of Mixed Beam-Solid Models for Analysis of Soil-Pile Interaction Problems. Ph.D. Dissertation, University of Washington.

Qiu, Z., Ebeido, A., Almutairi, A., Lu, J., Elgamal, A., Shing, P. B., and Martin, G. (2020). "Aspects of bridge-ground seismic response and liquefaction-induced deformations." Earthquake Engineering \&3 Structural Dynamics. doi: 10.1002/eqe.3244.

Russell, J., van Ballegooy, S., Ogden, M., Bastin, S., and Cubrinovski, M. (2017). "Influence of geometric, geologic, geomorphic and subsurface ground conditions on the accuracy of empirical models for prediction of lateral spreading." Proceedings of the 3rd International Conference on Performance Based Design in Earthquake Geotechnical Engineering (PBDIII), July 16-17, Vancouver, BC, Canada, Paper No. 216.

Spencer, E. (1967). "A method of analysis of the stability of embankments assuming parallel inter-slice forces." Géotechnique, 17(1), 11-26.

Tarbali, K. and Bradley, B. A. (2014). "Representative ground motion ensembles for several major earthquake scenarios in New Zealand." Bulletin of the New Zealand Society for Earthquake Engineering, 47(7), 231-252.

Turner, B. J. and Brandenberg, S. J. (2015). "Pile pinning and interaction of adjacent foundations during lateral spreading." DFI Journal - The Journal of the Deep Foundations Institute, 9(2), 92-102. doi: 10.1179/1937525515Y.0000000009.

Wotherspoon, L., Bradshaw, A., Green, R., Wood, C., Palermo, A., Cubrinovski, M., and Bradley, B. (2011). "Performance of bridges during the 2010 Darfield and 2011 Christchurch earthquakes." Seismological Research Letters, 82(6), 950-964. 
Youd, T. L. (1993). "Liquefaction-induced damage to bridges." Transportation Research Record No. 1411, 35-41.

Youd, T. L., Hansen, C. M., and Bartlett, S. F. (2002). "Revised multilinear regression equations for prediction of lateral spread displacement." Journal of Geotechnical and Geoenvironmental Engineering, ASCE, 128(12), 1007-1017.

Zhang, G., Robertson, P. K., and Brachman, R. W. I. (2004). "Estimating liquefactioninduced lateral displacements using the standard penetration test or cone penetration test." Journal of Geotechnical and Geoenvironmental Engineering, ASCE, 130(8), 861871. 


\section{List of Tables}

1 Model properties for soil layers in 3D FEA and ESA parameter study models. 30

$2 \quad$ Model material and section properties in parameter study deep foundations. 31 
TABLE 1. Model properties for soil layers in 3D FEA and ESA parameter study models.

\begin{tabular}{lccccc}
\hline Layer & $\rho\left(\mathrm{Mg} / \mathrm{m}^{3}\right)$ & $\phi\left(^{\circ}\right)$ & $G_{\max }(\mathrm{MPa})$ & $K_{\max }(\mathrm{MPa})$ & $S_{u}(\mathrm{kPa})$ \\
\hline dry loose sand & 1.7 & 32 & 75 & 200 & - \\
sat. loose sand & 1.7 & - & 6.0 & 175 & 5.0 \\
dense sand & 2.0 & 38 & 100 & 300 & - \\
embankment fill & 1.9 & 38 & 130 & 390 & - \\
\hline
\end{tabular}


TABLE 2. Model material and section properties in parameter study deep foundations.

\begin{tabular}{lccc}
\hline Diameter & $A\left(\mathrm{~m}^{2}\right)$ & $E(\mathrm{GPa})$ & $I\left(\mathrm{~m}^{4}\right)$ \\
\hline $0.6 \mathrm{~m}$ & 0.15 & 31.3 & 0.0038 \\
$1.4 \mathrm{~m}$ & 0.74 & 28.7 & 0.0869 \\
\hline
\end{tabular}




\section{List of Figures}

1 Example mesh and geometric layout for 3D FE model case with $1 \mathrm{~m}$ thick crust, $2 \mathrm{~m}$ thick liquefiable layer, and $4 \mathrm{~m}$ wide embankment crest. The boundaries where displacements are applied to simulate lateral spreading are indicated in red in the plan view of the mesh. The shape of the applied displacement profile (constant in embankment and crust, linear through liquefied layer, and zero in dense sand layer) is indicated in the $x$-z plane elevation view. 34

2 General layout of slope stability models and example failure surfaces for soil profiles with: (a) $1.5 \mathrm{~m}$ thick crust and $2 \mathrm{~m}$ thick liquefied layer; and (b) $1 \mathrm{~m}$ thick crust and $6 \mathrm{~m}$ thick liquefied layer. . . . . . . . . . . . . .

3 Summary of geometric configurations, including five liquefiable layer thicknesses (blue layer), five crust thicknesses (green layer), and four embankment crest widths (brown layer) . . . . . . . . . . . . . . . . 36

4 Deformed mesh (magnified 4 times) with contours of horizontal deformation for cases with $d=0.6 \mathrm{~m}, z=1.5 \mathrm{~m}$, and $t=3 \mathrm{~m}$. (a) Narrow embankment case with $w=4 \mathrm{~m}$; (b) Wider embankment case with $w=16 \mathrm{~m}$. Upper plots show a plan view of the $x-y$ plane and lower plots show an elevation view of the $x$ - $z$ plane (refer Fig. 1 for more information on the model layout). . . . . 37

5 Shaft displacement, shear force, and bending moment demands in 3D FEA for all combinations of liquefiable layer thickness $t$, thickness of non-liquefiable crust $z$, and embankment width $w(w 1=4 \mathrm{~m} ; w 2=8 \mathrm{~m} ; w 3=16 \mathrm{~m} ; w 4=$ full width) for the $0.6 \mathrm{~m}$ diameter pile. The thicknesses of the embankment fill and liquefiable zone are indicated by the tan and gray shaded zones, respectively. 38

6 Example compatible displacement determination for cases with $0.6 \mathrm{~m}$ diameter pile and $2 \mathrm{~m}$ thick crust. (a) $1 \mathrm{~m}$ thick liquefiable layer; (b) $2 \mathrm{~m}$ thick liquefiable layer; (c) $3 \mathrm{~m}$ thick liquefiable layer; (d) $4 \mathrm{~m}$ thick liquefiable layer. 39 
7 Compatible displacements with PGA for ESA cases with $0.6 \mathrm{~m}$ diameter pile. Marker color indicates: (a) tributary embankment width; (b) liquefiable layer thickness; (c) crust thickness. . . . . . . . . . . . . . . . . . . . 40

8 Compatible displacements with PGA for ESA cases with $1.4 \mathrm{~m}$ diameter pile. Marker color indicates: (a) tributary embankment width; (b) liquefiable layer thickness; (c) crust thickness. . . . . . . . . . . . . . . . . . . . . 41

$9 \quad$ Free-field lateral spreading deformation as indicated by LDI with PGA for all ESA cases. Marker color indicates: (a) Liquefiable layer thickness; (b) Crust thickness. . . . . . . . . . . . . . . . . .

10 ESA results with embankment width for $0.6 \mathrm{~m}$ diameter cases. Marker color indicates crust thickness. (a) Compatible displacements; (b) LDI; (c) Reduc-

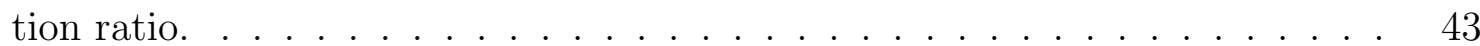

11 Variation of ESA and FEA results with crust thickness (ESA cases with $95 \leq$ LDI $\leq 105 \mathrm{~cm}$ only). (a) Compatible displacements from ESA for $0.6 \mathrm{~m}$ pile; (b) Pile head displacement from FEA for $0.6 \mathrm{~m}$ pile; (c) Compatible displacements from ESA for $1.4 \mathrm{~m}$ pile; (d) Pile head displacement from FEA for $1.4 \mathrm{~m}$ pile. . . . . . . . . . . . . . . . . . . . . . . . 44 


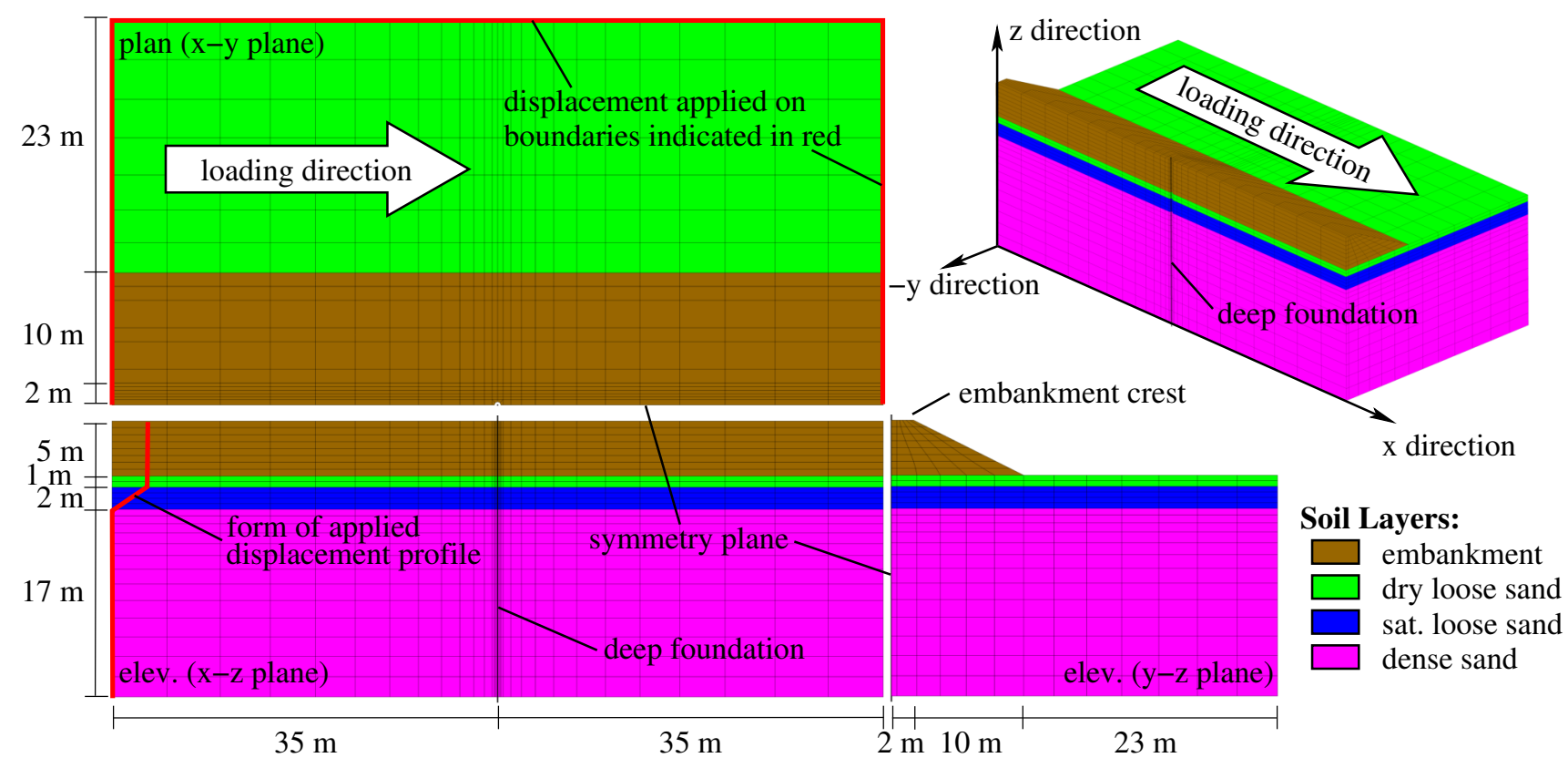

FIG. 1. Example mesh and geometric layout for 3D FE model case with $\mathbf{1} \mathbf{~ m}$ thick crust, $2 \mathrm{~m}$ thick liquefiable layer, and $4 \mathrm{~m}$ wide embankment crest. The boundaries where displacements are applied to simulate lateral spreading are indicated in red in the plan view of the mesh. The shape of the applied displacement profile (constant in embankment and crust, linear through liquefied layer, and zero in dense sand layer) is indicated in the $x-z$ plane elevation view. 


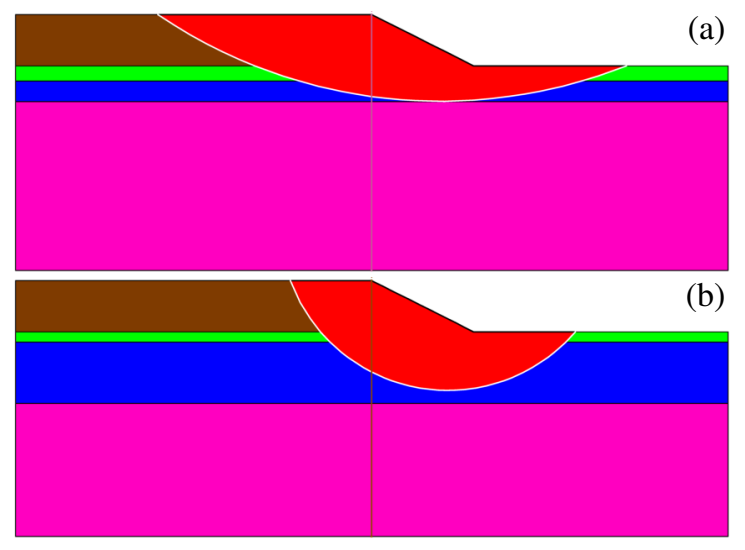

FIG. 2. General layout of slope stability models and example failure surfaces for soil profiles with: (a) $1.5 \mathrm{~m}$ thick crust and $2 \mathrm{~m}$ thick liquefied layer; and (b) $1 \mathrm{~m}$ thick crust and $6 \mathbf{m}$ thick liquefied layer. 


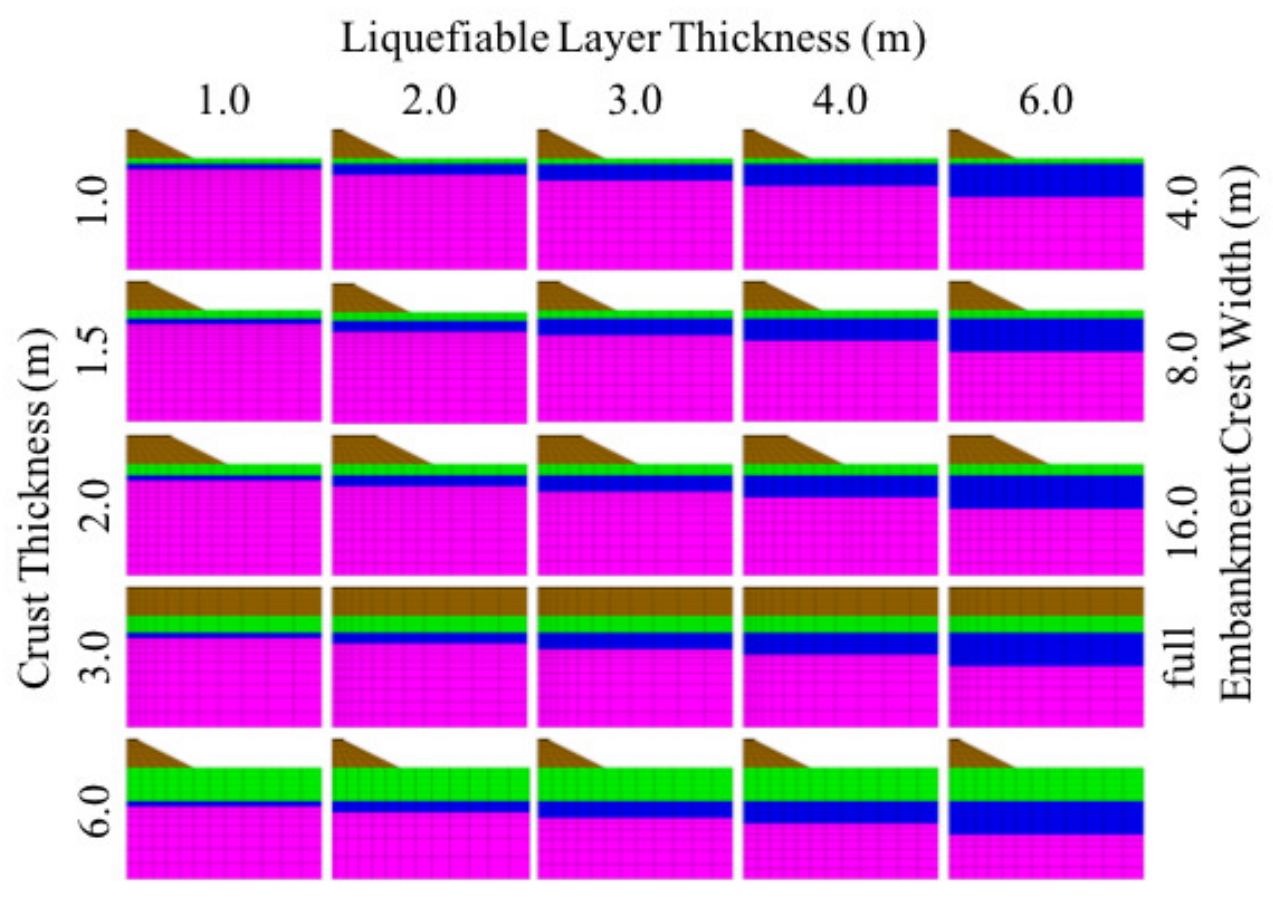

FIG. 3. Summary of geometric configurations, including five liquefiable layer thicknesses (blue layer), five crust thicknesses (green layer), and four embankment crest widths (brown layer). 

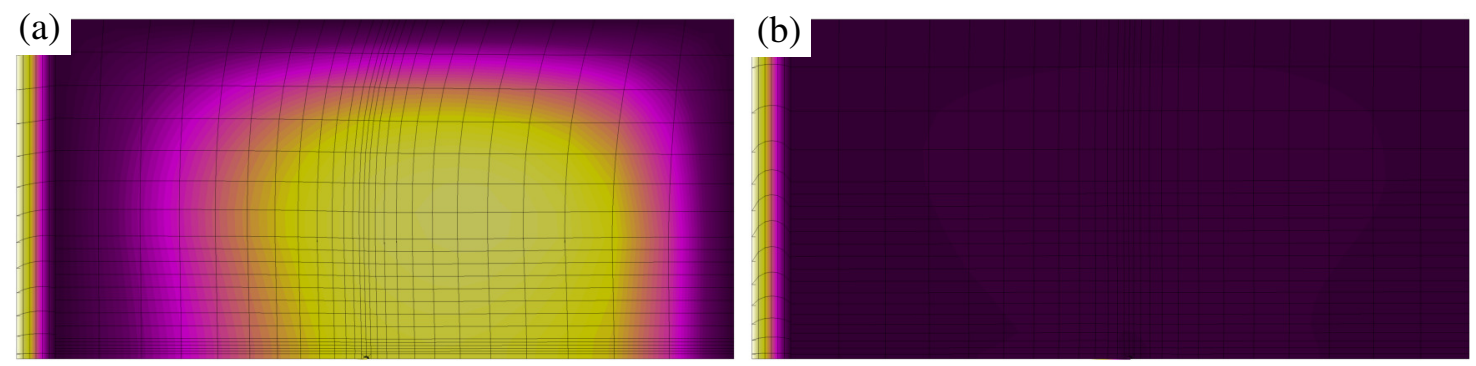

$100 \mathrm{~cm}$

$75 \mathrm{~cm}$
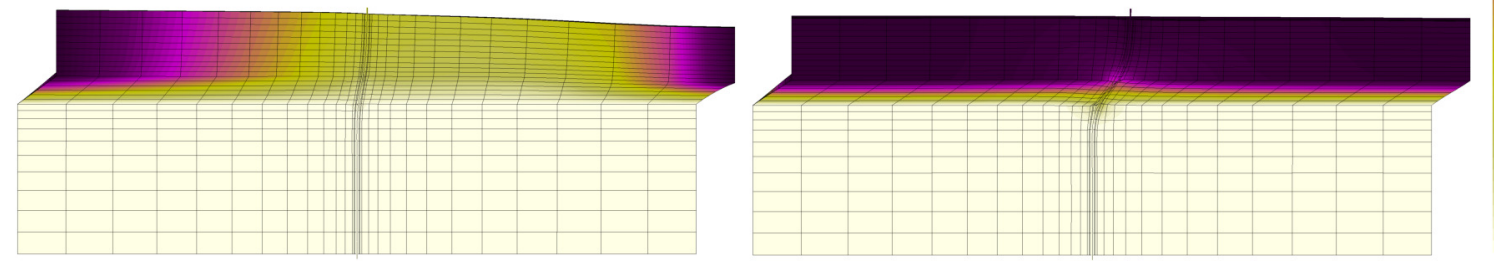

$50 \mathrm{~cm}$

$25 \mathrm{~cm}$

$0 \mathrm{~cm}$

FIG. 4. Deformed mesh (magnified 4 times) with contours of horizontal deformation for cases with $d=0.6 \mathbf{m}, z=1.5 \mathbf{m}$, and $t=3 \mathbf{m}$. (a) Narrow embankment case with $w=4 \mathbf{~ m}$; (b) Wider embankment case with $w=16 \mathbf{m}$. Upper plots show a plan view of the $x-y$ plane and lower plots show an elevation view of the $x-z$ plane (refer Fig. 1 for more information on the model layout). 


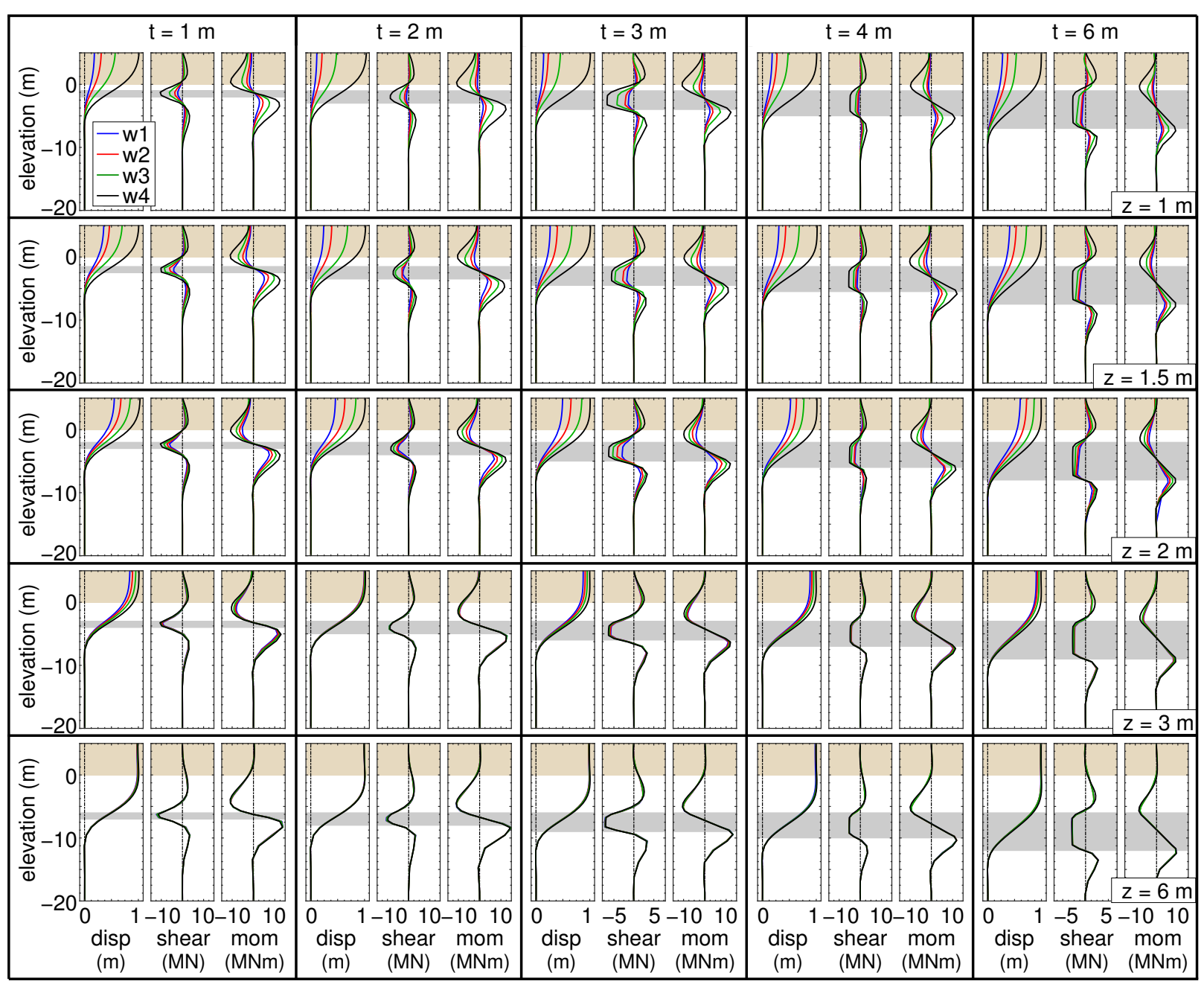

FIG. 5. Shaft displacement, shear force, and bending moment demands in 3D FEA for all combinations of liquefiable layer thickness $t$, thickness of non-liquefiable crust $z$, and embankment width $w(w 1=4 \mathbf{m} ; w 2=8 \mathbf{m} ; w 3=16 \mathbf{m} ; w 4=$ full width) for the $0.6 \mathbf{m}$ diameter pile. The thicknesses of the embankment fill and liquefiable zone are indicated by the tan and gray shaded zones, respectively. 


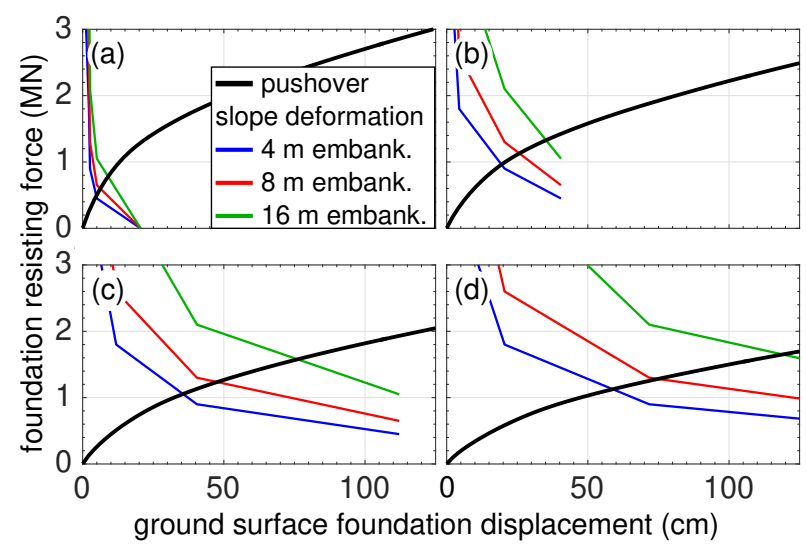

FIG. 6. Example compatible displacement determination for cases with $\mathbf{0 . 6} \mathbf{m}$ diameter pile and $\mathbf{2} \mathbf{m}$ thick crust. (a) $\mathbf{1} \mathbf{m}$ thick liquefiable layer; (b) $\mathbf{2} \mathbf{m}$ thick liquefiable layer; (c) $3 \mathrm{~m}$ thick liquefiable layer; (d) $4 \mathrm{~m}$ thick liquefiable layer. 


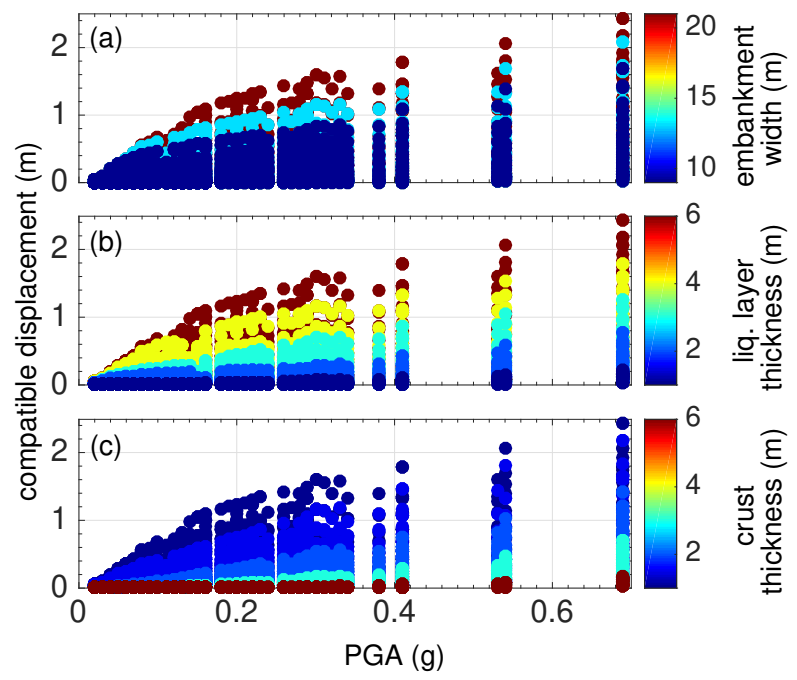

FIG. 7. Compatible displacements with PGA for ESA cases with $0.6 \mathrm{~m}$ diameter pile. Marker color indicates: (a) tributary embankment width; (b) liquefiable layer thickness; (c) crust thickness. 


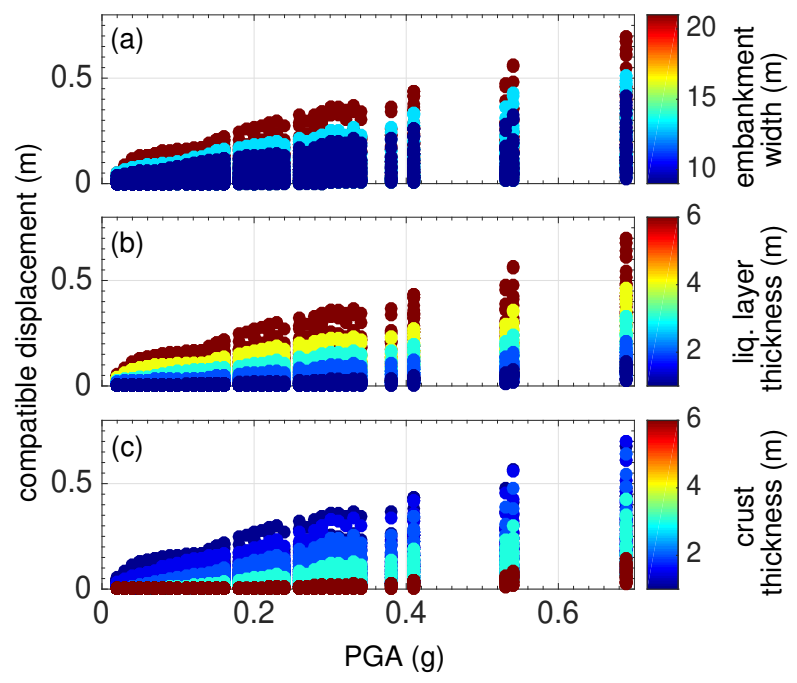

FIG. 8. Compatible displacements with PGA for ESA cases with $1.4 \mathrm{~m}$ diameter pile. Marker color indicates: (a) tributary embankment width; (b) liquefiable layer thickness; (c) crust thickness. 


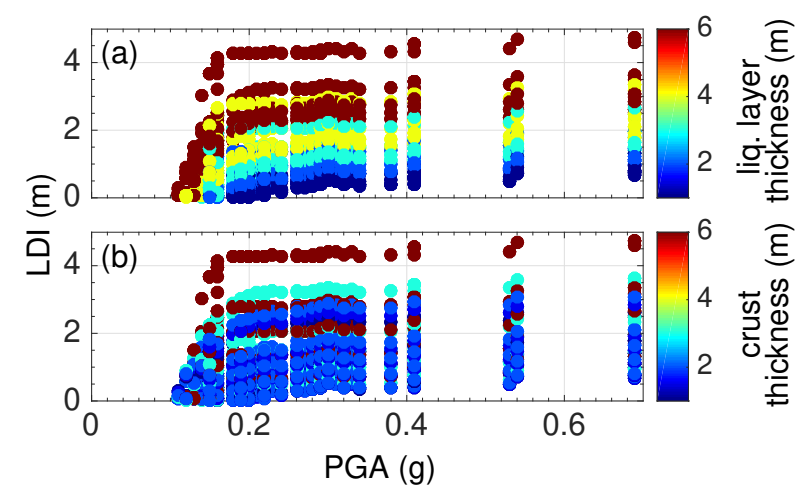

FIG. 9. Free-field lateral spreading deformation as indicated by LDI with PGA for all ESA cases. Marker color indicates: (a) Liquefiable layer thickness; (b) Crust thickness. 


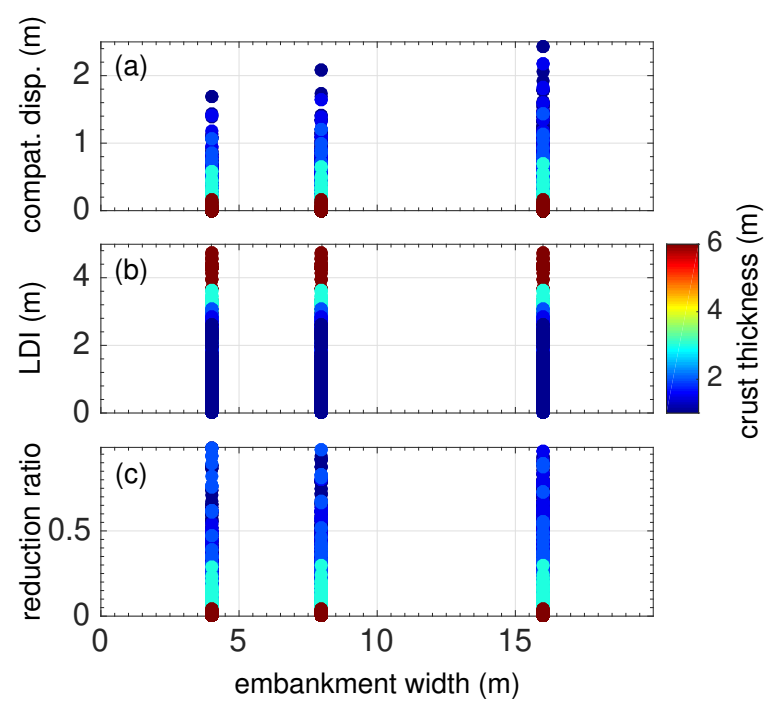

FIG. 10. ESA results with embankment width for $0.6 \mathrm{~m}$ diameter cases. Marker color indicates crust thickness. (a) Compatible displacements; (b) LDI; (c) Reduction ratio. 

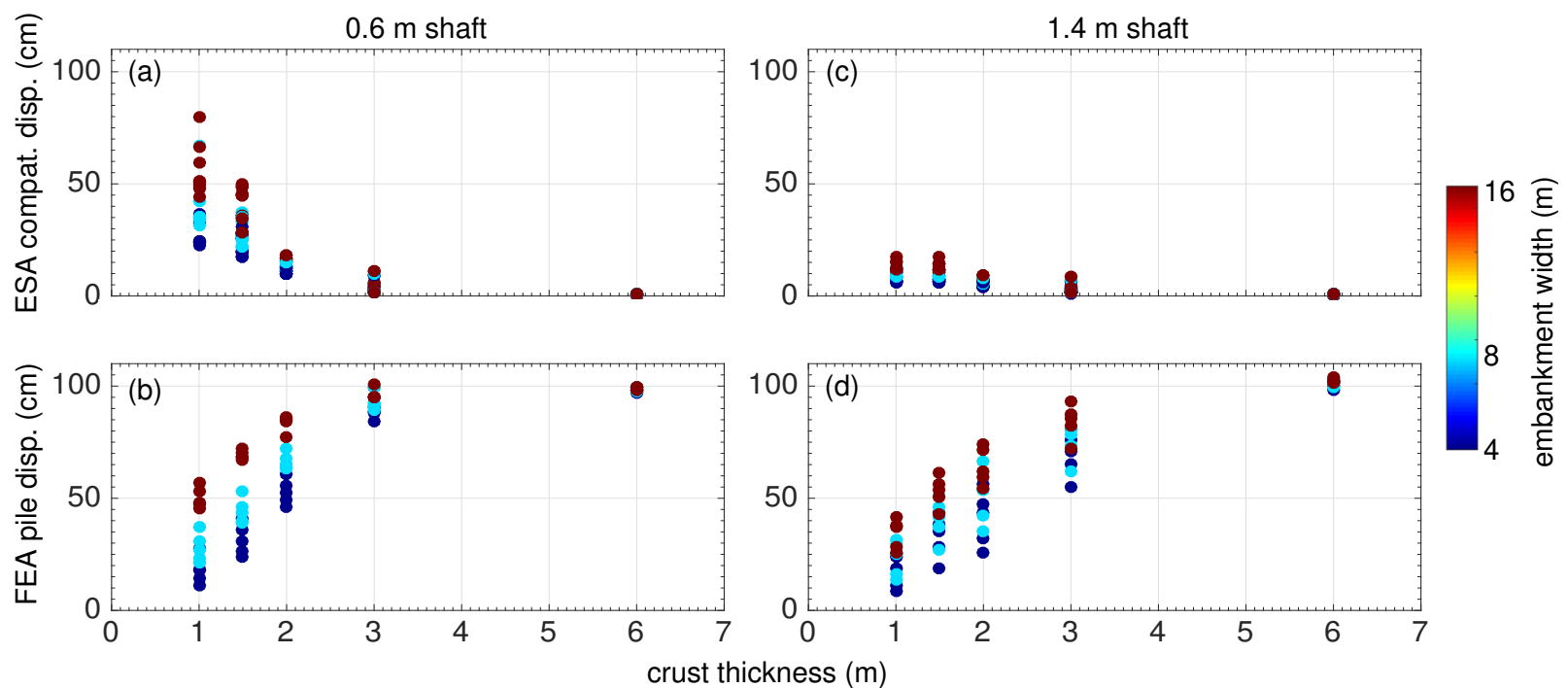

FIG. 11. Variation of ESA and FEA results with crust thickness (ESA cases with $95 \leq$ LDI $\leq 105 \mathrm{~cm}$ only). (a) Compatible displacements from ESA for $\mathbf{0 . 6} \mathbf{~ m}$ pile; (b) Pile head displacement from FEA for $\mathbf{0 . 6} \mathbf{~ m}$ pile; (c) Compatible displacements from ESA for $1.4 \mathrm{~m}$ pile; (d) Pile head displacement from FEA for $1.4 \mathrm{~m}$ pile. 